\title{
Juvenile pemphigus foliaceus
}

\author{
M.MEHRAVARAN, M.MORVAY, K.MOLNÁR, J.OLÁH, I.KOROM, S.HUSZ AND \\ A.DOBOZY \\ Department of Dermatology, Albert Szent-Györgyi Medical University, H-6701 Szeged, Korányi fasor 6, PO Box 480 , \\ Szeged, Hungary \\ Accepted for publication 7 April 1998
}

\begin{abstract}
Summary A 7-year-old girl with generalized erythematous, scaling plaques and vesiculobullous lesions on the extremities was diagnosed as having pemphigus foliaceus. Lesional direct immunofluorescence revealed intercellular IgG, IgA and C3 deposition. The patient's serum gave positive reactions against one epitope of desmoglein 3 and the epitope of desmoglein 1 in enzyme-linked immunosorbent assays, but the blood sample for indirect immunofluorescence did not display any circulating antibodies. The patient was successfully treated systemically with prednisolone and dapsone. Currently, she is taking dapsone, $12.5 \mathrm{mg}$ daily. She has been free of lesions for the last 3 years.
\end{abstract}

Pemphigus, a life-threatening autoimmune blistering disorder that involves the skin and mucous membranes, can be divided into two major subgroups: pemphigus vulgaris (PV) and pemphigus foliaceus (PF). ${ }^{1,2} \mathrm{PF}$, a superficial variant of pemphigus, is extremely rare in children and mostly occurs in the middle-aged and elderly. ${ }^{3,4}$ The clinical findings in childhood PF involve gradually spreading eczematized scaly plaques starting on the face and upper extremities, with the possible development of bullae and superficial crusts. ${ }^{5}$ Early diagnosis and prompt treatment are based on the clinical, histological and immunopathological changes.

\section{Case report}

A 7-year-old girl presented with a 3-month history of generalized, painful, small blisters and superinfected erosions covered with thick, yellowish crusts. For months, there had been a history of red, squamous plaques on the scalp, which were treated as psoriasis with local corticosteroids; the lesions healed slowly. The patient was weak and in a poor condition. Physical examination revealed extensive, generalized erythema, with superficial erosions covered with thick yellow crusts, mainly on the face (Fig. 1a), trunk (Fig. 2) and extremities. Scattered intact superficial blisters were present on the extremities, with a positive Nikolsky's sign. The oral mucosa was spared. Bilateral cervical and axillary lymphadenopathy was also noted.

Correspondence: Dr M.Mehravaran

E-mail: ME@derma.szote.u-szeged.hu
Laboratory investigations revealed the following abnormalities: leucocytosis with a white blood cell count of $20 \cdot 7\left(10^{9} / \mathrm{L}\right.$ (normal $\left.4 \cdot 6-10 \cdot 2\right)$, an aspartate aminotransferase level of $74 \mathrm{U} / \mathrm{L}$ (normal $<40 \mathrm{U} / \mathrm{L}$ ) and an alanine aminotransferase level of $83 \mathrm{U} / \mathrm{L}$ (normal $<40 \mathrm{U} / \mathrm{L}$ ). Skin and pharyngeal swabs for bacterial cultures were positive for Staphylococcus aureus and Streptococcus pyogenes.

A perilesional biopsy for histology demonstrated a subcorneal blister with acantholytic cells without any inflammatory cells in the cleft (Fig. 3). Direct immunofluorescence studies of frozen skin tissue showed positive intercellular staining for IgG, IgA and C3 within the epidermis. The circulating antidesmoglein 1 (anti-Dsg1) and anti-Dsg 3 antibodies were examined by means of enzyme-linked immunosorbent assays (ELISAs), using synthetic, antigenic peptides. Antigenic epitopes for desmogleins 1 and 3 were chosen using PeptideStructure software. The antigenic epitope for desmoglein 1 consists of 14 amino acids. It is part of the extracellular (EII) domain located between two $\mathrm{Ca}^{2+}$ binding sequences. The antigenic epitope for Dsg 3 consists of 13 amino acids. It is located in the extracellular (EI) domain and is part of the Bos1 sequence. ${ }^{6}$

Antigenic peptides were dissolved in phosphate-buffered saline (PBS), pH 7·4, in $0 \cdot 1 \mu \mathrm{g} / 100 \mu \mathrm{L}$ concentration. Microplate wells were filled with $100 \mu \mathrm{L}$ and allowed to coat overnight at $4{ }^{\circ} \mathrm{C}$. Plates were washed twice with distilled water, and the remaining binding sites were blocked with $1 \%$ bovine serum albumin (BSA) in PBS for $1.5 \mathrm{~h}$ at $37^{\circ} \mathrm{C}$. Plates were washed again three times with PBS-Tween (PBS containing 0.5\% 

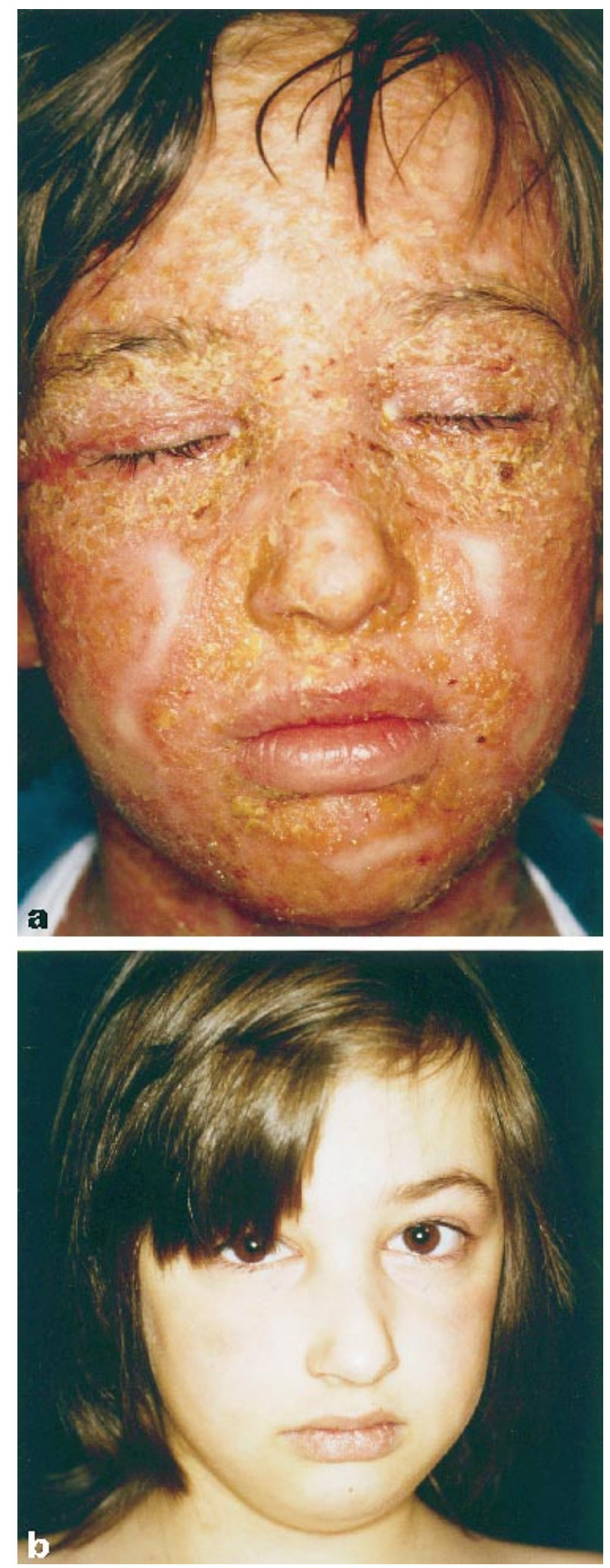

Figure 1. (a) Seborrhoeic-like, erythematous, scaling lesions are seen on the face. (b) Complete recovery with mild hyperpigmentation on the cheek.

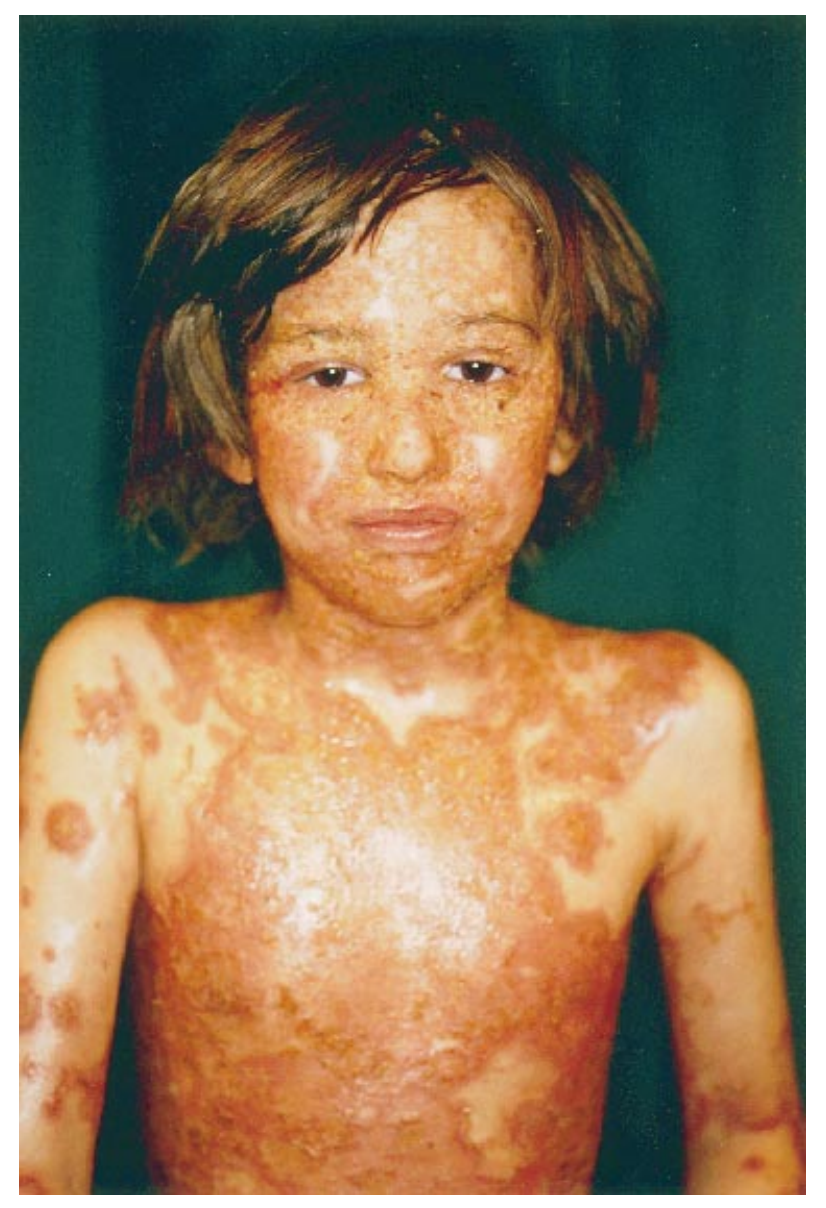

Figure 2. Diffuse, exfoliative, crusted, eroded plaques are evident on the trunk.

Tween-20), and $100 \mu \mathrm{L}$ of the 200 times diluted serum samples was added per well, incubated for $1 \mathrm{~h}$ at $37^{\circ} \mathrm{C}$ and washed extensively with PBS-Tween. Aliquots of $100 \mu \mathrm{L}$ of peroxidase-conjugated antihuman IgG, diluted $1: 5000$ in PBS-Tween, were then added to each well and incubated for $1 \mathrm{~h}$ at $37^{\circ} \mathrm{C}$. Subsequently, the plates were washed again with PBS-Tween and then $100 \mu \mathrm{L}$ of substrate solution [17 mg of ortho-phenylene diamine (OPD) dissolved in $50 \mathrm{~mL}$ of phosphate-citric acid buffer, $\mathrm{pH} 5$, and $20 \mu \mathrm{L}$ of $\mathrm{H}_{2} \mathrm{O}_{2}$ ] was added to each well and the colour allowed to develop for $10 \mathrm{~min}$ at room temperature in the dark. The reaction was stopped by adding $50 \mu \mathrm{L}$ of $4 \mathrm{~N} \mathrm{H}_{2} \mathrm{SO}_{4}$ to each well. Plates were read on an ELISA reader at $492 \mathrm{~nm}$.

In ELISA investigations, serum samples were tested in triplicate, and the mean results were taken. Ten healthy control sera were used in each microplate. Autoantibody positivity was accepted when special ELISA optical density was higher than the mean value of controls increased by two standard deviations. The patient's 


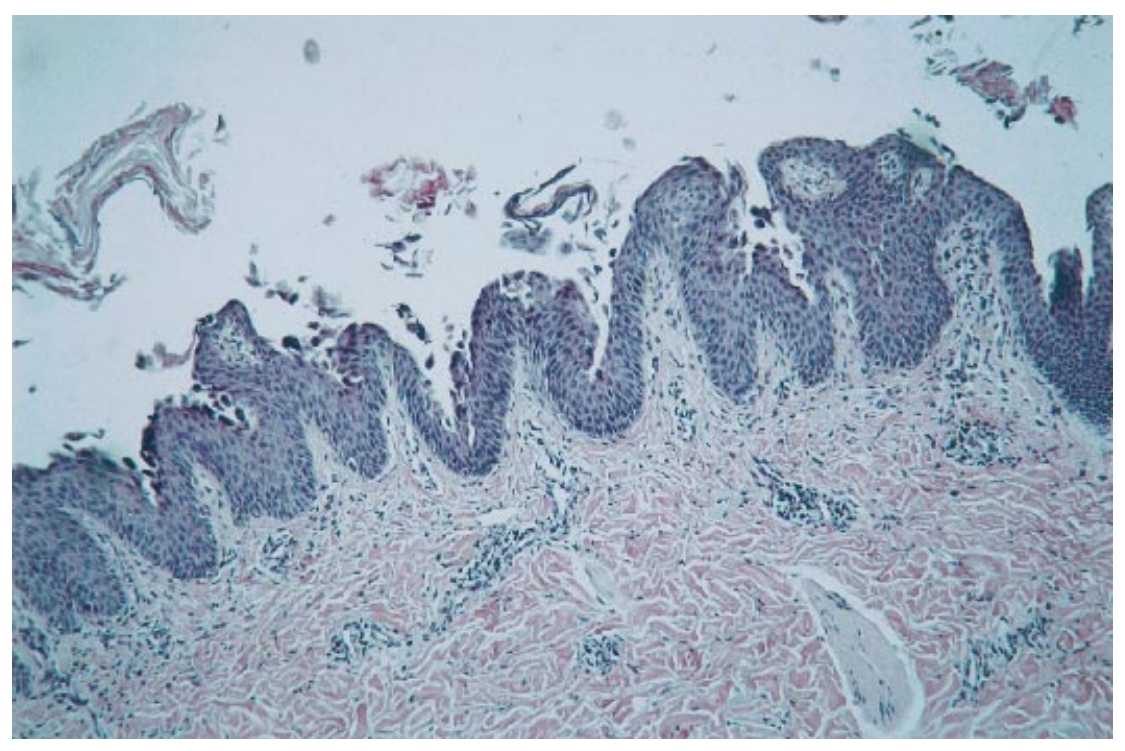

Figure 3. Acantholysis is present in the granular layer, with basophilic acantholytic cells inside the cleft (haematoxylin and eosin, original magnification, $\times 100)$. serum gave positive reactions against one epitope of Dsg 3 and the epitope of Dsg1. Blood samples for indirect immunofluorescence studies demonstrated no circulating antibodies. The patient's circulating anti-epidermal antibodies were also examined by the Western blot technique to detect Dsg1 or Dsg3, but there was no positive reaction.

A diagnosis of $\mathrm{PF}$ was made and treatment was commenced with $50 \mathrm{mg} /$ day prednisolone. This treatment resulted in only a slow remission, and we therefore combined the corticosteroid with $12.5 \mathrm{mg}$ of dapsone twice a day. In a few days, there was a satisfactory fast resolution of the blistering and a rapid improvement in the condition occurred. The dose of prednisolone was subsequently tapered slowly to half the initial dose. One month was sufficient for almost complete recovery (Fig. $1 b$ ), and blood investigations returned to normal. The patient was discharged while receiving $25 \mathrm{mg}$ of prednisolone every second day, and $12.5 \mathrm{mg}$ of dapsone twice daily. This treatment has been tapered so that she is now receiving $12.5 \mathrm{mg}$ of dapsone a day. She has had no further lesions over the last 3 years.

\section{Discussion}

$\mathrm{PF}$, a less severe variant of pemphigus, is a rare disease, especially in the first 14 years; it affects both sexes equally ${ }^{5,7-10}$ Despite its rarity, however, it is more frequent in Brazil ${ }^{11}$ and India. ${ }^{12}$ Adult $\mathrm{PF}$ has been reported to be associated with other autoimmune disorders ${ }^{13,14}$ and drugs, ${ }^{15}$ but Graves' disease is the only condition reported to coexist with childhood PF. ${ }^{9}$
The clinical manifestations of adult and juvenile PF are similar. The onset is often slow, with crusting, yellowish, scaling lesions starting on the face and scalp, as in our case, ${ }^{8}$ which can mimic impetigo and seborrhoeic dermatitis; unlike PV, the oral mucosa is rarely involved. ${ }^{5,7}$ Histologically, $\mathrm{PF}$ is characterized by acantholysis high in the epidermis, either subcorneally or in the stratum granulosum. ${ }^{16}$ These superficial changes are similar in PF and pemphigus erythematosus (PE) but, clinically, PE may simulate lupus erythematosus. ${ }^{17,18}$ Our case demonstrated the typical histology of PF, with acantholysis in the upper epidermis. $\mathrm{PF}$ in general gives identical immunofluorescence (IF) changes to PV. Staining of the PF lesions for direct IF shows the intercellular deposition of IgG, C3 and, rarely, $\operatorname{IgA},{ }^{19}$ as detected in our case. Serum from PF patients for indirect IF studies shows IgG staining of the keratinocyte cell surface in the upper epidermis. ${ }^{2}$

The pathogenesis of blister formation in pemphigus is related to the detection of autoantibody formation against PF antigen Dsg1 (160 kDa) and the PV antigen Dsg3 (130 kDa). ${ }^{20}$ Immunoblot analysis in PF patients revealed circulating autoantibodies against Dsg1 antigen; despite its potential positivity, the reaction was negative in two-thirds of the patients. ${ }^{21}$ These antigenic determinations including Dsg1 and Dsg 3 are important in differentiation from other autoimmune blistering diseases such as $\mathrm{PV}^{2}$ or $\mathrm{PE}$, which are not usually determined in PE. ${ }^{18}$ Therefore, detection of the characteristical anti-epidermal and anti-Dsg antibodies can support the diagnosis. In our case, investigation of the serum circulating antibodies using the Western blot 
technique did not detect any positive reaction but, based on more recent studies with ELISA, ${ }^{22,23}$ we also routinely examined the circulating anti-Dsg 1 and antiDsg 3 antibodies by means of ELISA using synthetic, antigenic peptides. ${ }^{24}$ The patient's serum gave positive reactions against one epitope of Dsg 3 and the epitope of Dsg1. We used these antigenic epitopes in more than 30 cases, and $68 \%$ of the sera from patients with pemphigus gave a specific reaction with these epitopes using the ELISA technique.

$\mathrm{PF}$, the less severe form of pemphigus, may be treated simply with topical steroids or low-dose corticosteroids; ${ }^{7}$ the more generalized form of PF has been treated with high-dose corticosteroids. ${ }^{9,25}$ However, Basset et al. ${ }^{26}$ reported satisfactory results with dapsone as initial therapy. We also achieved fast remission when we added dapsone to low-dose corticosteroids. We believe that PF is rare in childhood and has a good prognosis. As Basset et al. ${ }^{26}$ reported, we also achieved a good result with dapsone therapy. In our case, the lesions disappeared in response to a combination of dapsone and low-dose corticosteroids.

\section{References}

1 Korman N. Pemphigus. J Am Acad Dermatol 1988; 18: 121938.

2 Kawana S, Hashimoto T, Nishikawa T et al Changes in clinical features, histological findings, and antigen profiles with development of pemphigus foliaceus from pemphigus vulgaris. Arch Dermatol 1994; 130: 1534-8.

3 Ahmed AR, Salem M. Juvenile pemphigus. J Am Acad Dermatol 1983; 8: 799-807.

4 Sodiafy M, Vollum D. Pemphigus vulgaris in adolescence. Clin Exp Dermatol 1979; 4: 205-9.

5 Goodyear MH, Abrahamson LE, Harper IJ. Childhood pemphigus foliaceus. Clin Exp Dermatol 1991; 16: 229-30.

6 Bhol K, Natarajan K, Nagarwalla N et al Correlation of peptide specificity and IgG subclass with pathogenic and nonpathogenic autoantibodies in pemphigus vulgaris: a model for autoimmunity. Proc Natl Acad Sci USA 1995; 92: 5239-43.

7 Sotiriou L, Herszenson S, Jordan RE. Childhood pemphigus foliaceus: report of case. Arch Dermatol 1980; 116: 679-680.

8 Perry HO, Brunsting LA. Pemphigus foliaceus: further observations. Arch Dermatol 1965; 91: 10-23.

9 Levine L, Bernstein EJ, Soltani K et al Coexisting childhood pemphigus foliaceus and Graves' disease. Arch Dermatol 1982; 118: $602-4$.

10 Jones SK, Schwab HP, Norris DA. Childhood pemphigus foliaceus: case report and review of the literature. Pediatr Dermatol 1986; 3: 459-63.

11 Empinotti JC, Diaz LA, Martins CR et al. Endemic pemphigus foliaceus in Western Parana, Brazil. Br J Dermatol 1990; 123: 431-7.

12 Wojnarowska F, Bhogal B, Black MM et al. The immunofluorescence finding in Indian pemphigus. Br J Dermatol 1985; 112: 503-8.

13 Imamura S, Takigawa M, Ikai $\mathrm{K}$ et al Pemphigus foliaceus, myesthenia gravis, thyoma, and red cell aplasia. Clin Exp Dermatol 1978; 3: 285-91.

14 Falk ES. Pemphigus foliaceus in a patient with rheumatoid arthritis and Sjögren's syndrome. A case report. Dermatologica 1979; 158: 348-54.

15 Penas FP, Buezo FG, Carvajal I et al d-Penicillamine-induced pemphigus foliaceus without antibodies to desmoglein-I in patient with mixed connective tissue disease. J Am Acad Dermatol 1997; 37: 121-3.

16 Wilgram GF, Caufield JB, Madgic EB. An electron microscopic study of acantholysis and in pemphigus foliaceus: with the especial note of peculiar intracytoplasmic bodies. J Invest Dermatol 1964; 43: 287-99.

17 Chorzelski T, Jablonska S, Blaszczyk M. Immunopathological investigations in the Senear-Usher syndrome (coexistence of pemphigus and lupus erythematosus). Br J Dermatol 1968; 80: 211-17.

18 Lyde BC, Cox ES, Cruz DP. Pemphigus erythematosus in a five-yearold child. J Am Acad Dermatol 1994; 31: 906-9.

19 Beutner EH, Chorzelski TP, Wilson RM et al. IgA pemphigus foliaceus. J Am Acad Dermatol 1989; 20: 89-97.

20 Amagai M. Adhesion molecules. I. Keratinocyte-keratinocyte interactions; cadherins and pemphigus. J Invest Dermatol 1995; 104: 146-52.

21 Emery DJ, Diaz LA, Fairley JA et al. Pemphigus foliaceus and pemphigus vulgaris autoantibodies react with the extracellular domain of desmoglein-1. J Invest Dermatol 1995; 104: 323-8.

22 Hernandez C, Amagai M, Chan LS. Pemphigus foliaceus: preferential binding of IgG1 and $\mathrm{C} 3$ at the upper epidermis. Br J Dermatol 1997; 136: 249-52.

23 Ishii K, Amagai M, Hall RP et al. Characterization of autoantibodies in pemphigus using antigen-specific enzyme-linked immunosorbent assays with baculovirus-expressed recombiant desmogleins. J Immunol 1997; 159: 2010-17.

24 Husz S, Kiss M, Marczinovits I et al Detection of bullous pemphigoid antibodies by means of synthetic peptides as antigenic epitopes. Acta Microbiol Immunol Hung 1996; 43: 339-43.

25 Schroeter A, Sams WM Jr, Jordan RE. Immunofluorescence studies of pemphigus foliaceus in a child. Arch Dermatol 1969; 100: 73640 .

26 Basset N, Gillot B, Bruno M et al Dapsone as initial treatment in superficial pemphigus. Arch Dermatol 1987; 123: 783-5. 